\title{
A EDUCACC̃̃O FRENTE ÀS TENDÊNCIAS LIBERAL E COMUNITARISTA DA DEMOCRACIA
}

\author{
EDUCATION IN FACE OF LIBERAL AND \\ COMMUNITARIAN TENDENCIES OF DEMOCRACY \\ L'ÉDUCATION FACE AUX TENDENCES LIBÉRALES ET \\ COMMUNAUTAIRES DE LA DÉMOCRATIE \\ LA EDUCACIÓN FRENTE A LAS TENDENCIAS LIBERAL \\ Y COMUNITARISTA DE LA DEMOCRACIA
}

\author{
Sidney Reinaldo da Silva *
}

\begin{abstract}
RESUMO
O objetivo deste texto é contrapor modelos de democracia para investigar a gestão da educação, discutindo o potencial heurístico desses modelos na compreensão dos desafios da administração democrática do ensino e da forma como as políticas educacionais são concebidas e implementadas na escola pública. São abordadas a concepção contratualista ou liberal da democracia e a sua concepção comunitarista ou participativa. Mostra-se que essas concepções, por mais que se contraponham, se entrecruzam e precisam uma da outra para se autodefinirem, fazendo parte de uma mesma família ético-politica. A despeito de sua crítica ao individualismo e à lógica do contrato social como base para a democracia, a concepção comunitarista não é incompativel com as exigências capitalistas, permitindo a esse sistema se rearticular politicamente a partir de novas bases éticas.
\end{abstract}

Palavras-chave: Modelos ético-politicos. Democracia. Gestão da educação.

* Doutor em Filosofia pela Universidade Estadual de Campinas (Unicamp, 1999). Pós-doutor em Filosofia e História da Educação pela Faculdade de Educação da Unicamp (2003). Professor Adjunto do Mestrado em Educação da Universidade Tuiuti do Paraná (sidney.silva@utp.br). 


\section{INTRODUÇÃO}

Este texto aborda, numa perspectiva ético-política, a relação entre democracia e educação, contrapondo modelos de democracia para se pensar e atuar na escola a partir de certos valores e de certas racionalidades. São analisadas duas tendências da democracia: a concepção contratualista ou liberal da democracia e a concepção comunitarista ou participativa. Contrapõem-se "modelos" de democracia para investigar a gestão da educação, apontando o potencial heurístico desses modelos para se compreender as políticas educacionais e a administração democrática da escola pública. Destacam-se, sobretudo, as formas como eles se contrapõem como duas lógicas da deliberação pública, constituindo-se em duas concepções normativas divergentes para se pensar a democracia e suas exigências. Mostra-se, contudo, que essas concepções, muitas vezes, apresentamse tão próximas, em certas combinações, que seria impossível negar que fazem parte de uma mesma família ético-política, que se entrecruzam e precisam uma da outra para se autodefinirem. A questão é muito mais de se investigar as possibilidades de se ir além delas e de resgatar dimensões da vida democrática que escamoteiam, sobretudo no sentido de descortinar formas de gestão da educação comprometidas com a soberania popular e a rediscussão do papel ativo do Estado numa democracia.

A relação entre liberalismo, comunitarismo e educação vem sendo debatida nas últimas décadas, sobretudo por autores ligados à discussão da teoria da justiça, tal como Gutmann (1987); à cidadania, como Torres (2001); e por estudiosos do currículo, como Forquin (2000). No presente artigo, a dimensão normativa da democracia é tomada como construção ético-política sobre o terreno das relaçôes produtivas, ao qual estão vinculados conceitos e procedimentos considerados válidos num determinado momento. Cabe retomar o que disse Marx no texto a Miséria da Filosofia: "os mesmos homens que estabelecem as relações sociais de acordo com a sua produtividade material produzem, também, os princípios, as ideias, as categorias de acordo com as suas relações sociais" (MARX, 1985, p. 102). Sendo produtos históricos, os procedimentos e concepções da democracia, tais como as ideias e as categorias, são tão transitórios quanto as relações materiais que os exprimem. Nesse sentido, teorias e modelos normativos dizem respeito a tendências históricas. No âmbito das ciências sociais, quando questôes normativas estão em foco, o modelo garante sua efetividade na medida em que não se distancia dos projetos e práticas concretas, sem o que ele perde sua eficácia heurística e transformadora da realidade. Assim os modelos de democracia abordados constituem-se em desafios práticos, projetos a serem seguidos, reformulados ou evitados.

\section{SOBRE OS MODELOS ÉTICO-POLÍTICOS}

O problema ético-político mais básico da democracia refere-se à possibilidade ou não de se conceber um ponto de vista comum e compartilhado, que supostamente permitiria uma avaliação imparcial das questões a serem decididas coletivamente, o que tem sido 
denominado de "ponto de vista moral". Éticas formalistas indicam regras que especificam como algo pode ser considerado do ponto de vista moral. Mas como pensar questôes de democracia a partir de investigações da vida concreta, tal como ocorre na escola e nos espaços onde se tomam decisões sobre a educação? Como conceber esse ponto de vista comum, de onde se delibera a respeito do tipo de educação que se quer e de como garanti-la? Caso se pressuponha que tal ponto de vista partilhado não possa existir, devido à pluralidade de perspectivas (ligadas à desigualdade de classe social, às diferenças culturais, de gênero, etnias, ente outras), como pensar a gestão democrática num prisma ético-político em que uma decisão, uma lei ou comando comum esteja em jogo?

De qualquer modo, hoje se fala em gestão democrática da educação e isso indica que há um "espaço" produtor de normas e de justificação, por mais que esse "espaço" se apresente dissolvido e fragmentado. Sendo assim, a investigação dessa dimensão ético-política não é um exercício intelectual sobre uma quimera. Ela torna-se mesmo necessária quando se quer compreender a gestão democrática, especialmente, no presente caso, da educação e da escola. A questão é a de como pensar esse "espaço", isto é, de como conceber modelos para localizá-lo, para atuar democraticamente sobre ele e não apenas em seu interior.

Modelos, assim como as teorias, são formas de mostrar e ver. Tornam visível o que empiricamente não aparece, o que não é dado de forma imediata. Mas os modelos mostram também como algo deve ser (visto). E nesse caso o como se torna-se um dever ser, que, no âmbito das decisões coletivas, corresponde a um quadro prescritivo de como as decisões e os acordos deveriam ser feitos para serem legítimos ou para se coadunarem com valores democráticos. Não se trata de ir tão longe a ponto de reduzir tudo a tipos ideais, ou a condicionamentos paradigmáticos ou culturais, como fazem, respectivamente, adeptos das escolas webberiana e kuhniana.

É inegável que "quando uma ciência examina uma questão, ela se baseia nos pressupostos de seu paradigma” (FOUREZ, 1995, p. 297). Mas os modelos são constructos vinculados a ideologias e se comprometem em mostrar ou esconder coisas conforme interesses sociais em conflito. Nesse sentido, os conflitos ligados às lutas pela produção material da existência são "anteriores" aos paradigmas. Entretanto, não se trata de um outro tipo de reducionismo, na medida em que essas dimensões da realidade humana são indissociáveis, constituindo-se numa espécie de via de mão dupla embaralhada para se investigar a sociedade. O que poderia ser considerado "lógica" ou "ontologicamente" posterior ou derivado não perde seu caráter heurístico na medida em que suas contradições vinculam-se ao âmbito no qual é concebido como derivado.

Os modelos são correlatos das teorias. A palavra teoria é compreendida como o exercício do olhar da inteligência (ROMANO, 2001, p. 55). Tal como o termo intuitus no latim, que significa 'golpe de vista'. Como ato de olhar, a teoria e a intuição são concebidas como correlatas da mente especulativa, da mente tomada "como" espelho. Nesse prisma, modelos são paradigmas, no sentido de moldar o olhar (a percepção). 
Enquanto formas de mostrar e ver, os modelos referem-se ao conceito de visibilidade, que, numa perspectiva ético-política, pode ser definido como um esquema de transparência, segundo o qual se delibera hipoteticamente, no sentido de propor o que seria desejável e factível, quando se afirma (ou se nega), por exemplo, a necessidade de um Estado como condição de possibilidade da co-existência "civilizada" entre indivíduos, quando se pensa seu desenho institucional, suas funçôes, suas prerrogativas e seus limites. Nesse sentido, retomo aqui a concepção de transparência, de Romano (2001). Esse filósofo a destaca como uma metáfora ótica, um "instrumento" talhado como prisma, que se encontra constantemente presente em enunciados filosóficos jurídicos, ou seja, éticopolíticos. No campo axiológico, o termo apresenta os seguintes traços:

Paradigma é uma palavra que surge na língua antiga ligada a deiknumi, cujo sentido é 'mostrar', 'demonstrar', 'indicar'. O paradigma une a sapiência à óptica. Quando o termo deiknumi é acrescido da partícula para, como em paradigma, ele significa 'mostrar, fornecer um modelo'. Essa ideia não remete apenas ao desvelamento de uma ilusão ou mentira mas possui um traço positivo. A raiz deik - também presente em paradigma - refere-se sobretudo ao ato de 'mostrar mediante a palavra', mostrar 'o que deve ser'. Daí a união interna com a diké, a lei, a norma, a regra (ROMANO, 2001, p. 54).

Partindo dessa concepção de transparência/visibilidade, retomo os modelos como determinada organização mental, como uma matriz que estrutura a percepção, estruturando, portanto, a realidade tal como ela passa a ser apresentada para nós. Na medida em que não podemos nos desfazer dos modelos para ter acesso à realidade "tal como ela é em si”, os modelos são a realidade para nós e a nossa realidade acaba sendo também uma modelagem, cuja chave interpretativa é a produção e reprodução da existência humana. Considerado como um objeto abstrato (não físico), um modelo pode ser percebido como um determinado "paradigma". Nesse sentido, Fourez (1995, p. 105) mostra que "existe um certo número de regras, princípios, estruturas mentais, instrumentos, normas culturais e/ou práticas, que organizam o mundo antes de seu estudo mais aprofundado". No âmbito das ciências sociais, quando questôes normativas estão em foco, o modelo garante sua efetividade na medida em que não se distancia dos projetos e práticas concretas, sem o que ele perde sua eficácia heurística e transformadora da realidade. A esse respeito pode se dizer que:

Embora uma teoria normativa da democracia seja necessária em qualquer projeto que aspire a promover a democratização substantiva da vida pública, o certo é que uma tal teoria deve ter também um potencial de análise empírica e uma capacidade de orientação da ação fundamentada na detecção de processos e atores sociais e políticas reais, portadores de projetos que promovam a democracia integral desejada (DAGNINO; OLVERA; PANFICHI, 2006, p. 20).

No campo da política, a construção de um modelo tem em vista justificar determinado estado de coisas ou propor um novo estado de coisas afirmando-o como viável 
e mesmo necessário do ponto de vista democrático. Nesse sentido, por exemplo, um modelo deliberativo do contrato social constrói e apresenta um ponto de vista éticopolítico. Como diz Oña (1985), o contrato perde sua capacidade de generalizar interesses e se converte em garantia - segundo a ficção consensual - dos interesses dominantes. $\mathrm{Na}$ atualidade, outras concepções se contrapóem à teoria contratualista, constituindo novos modelos para se investigar a democracia. De qualquer modo, é destacável que a teoria do contrato, que funda a democracia burguesa moderna, é ponto de partida para se compreender novas concepçóes de democracia que sobrevieram na contemporaneidade.

É frente a esse horizonte ético-político que são contrapostos "modelos" de democracia para se investigar a gestão da educação. Os modelos são reapresentados no sentido de indicar formas de democracia que têm sido não apenas concebidas filosoficamente, mas também historicamente construídas e que têm sido apresentadas como "paradigmas" da gestão democrática.

\section{A DEMOCRACIA CONTRATUALISTA E A GESTÃO DA EDUCAÇÃO}

O contrato social é concebido como um tipo de jogo em que cada jogador pode e deve considerar simultaneamente as perspectivas de todos os demais jogadores. A questão é a de saber como integrar as diversas perspectivas para se conceber um ponto de vista comum. A construção de uma vontade comum exige a concepção de um ponto de vista partilhado, uma perspectiva que seria moral, a partir da qual ocorreria o decreto racional instituidor da sociedade civil (governo, leis, polícia... o projeto político pedagógico, o currículo e a avaliação escolar). Isso exigiria uma framework (armação, estrutura) a partir da qual se responda (coletivamente) a questôes sobre a legitimidade das obrigaçôes éticopolíticas assumidas.

Segundo o esquema de Ackerman (1980), o contrato configura-se na seguinte forma:

1. os indivíduos que escolhem " $c$ ";

2. a situação da escolha " $C$ ";

3. as alternativas de escolhas " $\mathrm{A}$ "

Tem-se o seguinte quadro prático: se "c" escolhe " $\mathrm{S}$ " na situação "C", isto estabelece a legitimidade de " $S$ " somente em relação a uma especificação dos que escolhem, da situação e das alternativas a serem escolhidas. Assim, um contrato deve ser concebido somente como um evento contextualizado, e não como um evento universalizável. De qualquer forma, na tradição contratualista se pensou num acordo com características universalizáveis. Semelhante universalidade acompanhou-se da pretensão de neutralidade. Contudo, como mostra Oña (1985), a ficção do contrato pode tornar-se um instrumento a favor dos mais diversos regimes políticos, de modo que não se pode considerar nenhum procedimento como neutro (p. 208). 
As mais novas expressões da abordagem liberal contratualista são certas concepções de gestão em rede, correlacionadas nas parcerias e convênios, bem como a proposta do "contrato de gestão" para escolher diretores e avaliar a administração das escolas. Da mesma forma pode-se pensar o Projeto Político Pedagógico como sendo um momento de instauração do contratual, onde seria negociado o tipo de escola que se quer. Há quem fale e mesmo advogue e contraponha o contrato pedagógico e/ou didático entre professor e alunos (BROUSEAU, 1988; PINTO, 2003).

Um estudo mais específico da escola, conforme o pensamento liberal, foi realizado por Gutmann (1987). Ela indica as características específicas de uma escola multicultural, propondo uma formação "cívica" de modo a conciliar o multiculturalismo, a democracia e o liberalismo. Escolas devem apresentar um propósito cívico partilhável por todos os cidadãos. Trata-se de buscar um equilíbrio entre as exigências exageradas de uniformidade do "universalismo transcendental" e as expectativas demasiado restritas de uniformidade dos particularistas que propõem escolas separadas. Os valores da escola liberal multiculturalista seriam: as liberdades básicas, a igualdade de oportunidades e a deliberação baseada em procedimentos justos.

A legitimidade do contrato surge da forma como são construídos as regras e os valores, bem como são tomadas as decisões coletivas, o seu procedimento. A partir da teoria do desenvolvimento do juízo moral de Piaget, a tradição do contrato social passou a ser concebida como a forma mais adequada de se praticar a democracia na escola, de modo a favorecer e respeitar a formação da autonomia dos indivíduos. Contudo, cabe ressaltar que, para a tradição liberal, a participação não é um bem em si mesmo, mas um meio para que a criança desenvolva sua autonomia num ambiente não autoritário.

Segundo Gutmann (1995), a participação só tem razão de ser na medida em que promova a autonomia da pessoa. A participação é vista como meio para promover a autonomia. "O teste de uma instituição democrática não é a participação direta de todos e sim a responsabilização efetiva de todos os que tomam decisões perante todos os que não as tomam” (p. 24). Portanto, central para a democracia deliberativa, tal como a entende a autora, é a exigência de prestação de contas, e não a participação direta. A participação não é um bem que deve ser promovido a qualquer "preço". A participação é importante, do ponto de vista formativo, quando ela propicia a formação de pessoas razoáveis, ou seja, capazes de negociar com espírito de equidade, tolerância, e de propor e aceitar acordos somente quando são compreendidos como decentes.

Críticos apontam para os perigos dos falsos contratos, daqueles que o seriam meramente na aparência. Conforme Santos (1999), a nova contratualização dada em torno do Consenso de Washington seria um falso contrato. Malgrado a crítica à falsificação do contrato, Santos acredita numa forma legítima de contratualismo. Para ele, a redescoberta da democracia passa pela exigência de um novo contrato social cosmopolita. $\mathrm{O}$ falso pacto seria: 
uma mera aparência de compromisso constituído por condições impostas sem discussão ao parceiro mais fraco no contrato, condições onerosas quando inescapáveis. Sob a aparência do contrato, a nova contratualização configura a reemergência do status, ou seja, dos princípios de ordenação hierárquica pré-moderna onde as condiçóes das relações sociais estavam diretamente ligadas às posiçôes das partes na hierarquia social. De fato, não se trata de um regresso ao passado. O status agora é apenas o efeito da enorme desigualdade de poder econômico entre as partes no contrato individual e na capacidade que tal desigualdade dá à parte mais forte para impor discussão as condições que lhe são mais favoráveis. O status pós-moderno manifesta-se como contrato leonino (SANTOS, 1999, p. 96).

O contratualismo de Santos retoma a temática da diferença e da correlação entre o local e o geral e do apelo à comunidade e aos movimentos sociais. Destaca-se também a recusa da importância ou centralidade do Estado nacional para a democracia. Essa proposta está em consonância com aquilo que Tedesco (1998) chamou de um "novo pacto educativo". Com esse autor, a recusa da articulação da democracia no âmbito do estado nacional, constituído como centro das deliberações coletivas, liga-se a uma proposta de negociaçôes em rede. Trata-se, segundo ele, de superar o contratualismo proposto por Rawls, baseado numa "estratégia mais global”, que, a partir da ideia de véu da ignorância, buscou "tratar todos da mesma maneira, independente de suas condiçóes particulares", concepção que teria servido para moldar a "atividade educativa tradicional" (1998, p. 105). Refuta-se o modelo deliberativo igualitário e homogêneo em que todos são tratados da mesma maneira, como ocorre nas políticas universalistas, cujo principal agente é o Estado nacional. Segundo Tedesco, as diferenças não podem mais ser ignoradas nos acordos em torno da educação, que tenderiam a gerar discriminação quando tratam de modo igual os diferentes (1998, p. 105). O autor argentino propõe o fortalecimento da autonomia local e a integração em rede como a única forma eficaz de democratização da gestão das instituições educacionais:

Mas a característica fundamental de uma rede, em comparação com os sistemas hierárquicos tradicionais, é que ela pode ser mobilizada pelas iniciativas de cada um dos participantes e usuários, e não só de sua cúpula, de seu proprietário ou de seu construtor. A lógica da rede é, desse ponto de vista, potencialmente muito mais democrática que a lógica do sistema. Essa democratização refere-se, em particular, ao funcionamento interno, aos mecanismos de comunicação e de intercâmbios (...) (TEDESCO, 1998, p. 117).

Santos (1999) e Tedesco (1998) retomam as ideias de "contrato" e "pacto" social buscando purificá-las dos desvios sofridos historicamente, chamando, respectivamente, a atenção para o âmbito cosmopolita dos acordos e para os aspectos ligados às diferenciações internas na sua dimensão subnacional. Ambos recusam a centralidade do Estado nacional, e ambos chamam a atenção para as comunidades e as diferenças.

Contudo, esses autores se afastam da concepção liberal do contrato, na medida em que reconhecem a importância da participação das comunidades como indispensável 
para a democracia. A concepção liberal de democracia não vê na participação uma virtude, nem, muito menos, uma forma de dar sentido à vida, uma vez que não pressupõe que faz parte da natureza humana a necessidade de participação política. Concebe-se tal participação meramente como instrumental, como um meio para se garantir e defender os direitos civis, as liberdades individuais. Assim, a participação dependerá do cálculo utilitarista individual, segundo o qual se define a relação custo benefício do "engajamento" político. As acepções da democracia contratualista voltadas para sua dimensão ética, não instrumental, e mesmo comunitária da política, mostram um hibridismo com as concepções da democracia não contratualista, que, em muitos casos, se agrupam sob o rótulo de democracia deliberativa, cujo sentido é também muito variável.

\section{A DEMOCRACIA COMUNITARISTA: RECONHECIMENTO E IDENTIDADE COMO BASE PARA A FORMAÇÃO HUMANA}

São destacadas agora críticas ao contratualismo que negam sua lógica como base para a democracia, que dão lugar a novas concepções de participação cidadã, sobretudo aquelas em que a comunidade e as tradições tornaram-se a referência e não mais o indivíduo. No caso, o comunitarismo nega o contrato social como base para a decisão coletiva, sobretudo porque o esquema deste supõe uma abstração dos agentes num modelo que na prática não seria operacional. Entende-se agora que quem toma decisões são pessoas cuja filiação a uma comunidade e tradição não pode ser suprimida ou depurada para se concebê-las calculando como agentes supostos, como meramente livres e racionais. Contudo, as críticas feitas pelo comunitarismo ao princípio do contrato social não rompem o ideário econômico liberal mais abrangente. Ruiz Schneider (2000, p. 6) mostra que a crítica do comunitarismo ao liberalismo enfatiza:

los significados y los bienes comunes, en la participación y la acción politica y en la construcción de una comunidad politica autogobernada, frente al ideal liberal de unos individuos autónomos que ejercen sus preferencias individuales en un Estado mínimo y neutro. La crítica comunitaria y republicana, a diferencia de la crítica conservadora, no busca de ninguna manera terminar con el liberalismo. Aspira, por una parte, a mostrar las condiciones que lo hacen posible históricamente y, por otra, a explicitar los compromisos comunitarios mucho más amplios que requieren la defensa de la autonomía y de la libertad, que nos llevan entonces también mucho más allá de ellos, hacia un compromiso de solidaridad y participación no instrumental en la vida pública, considerada como una forma de construcción deliberativa de identidades y relaciones que saca a los individuos aislados de su impotencia y su sinsentido.

Tem-se que a comunidade passa a ser indispensável para a democracia, tomada como forma de vida em que a cooperação não se desvincula da solidariedade e da responsabilidade, como modo de combater os males oriundos da competição e da racionalidade individual fechada ao outro, e que visa concebê-lo meramente como recurso, meio e 
objeto. Como mostra Bauman (2003), a obrigação fraterna ligada à comunidade exige que se partilhe as vantagens e benefícios entre seus membros, independente do talento ou importância de cada um. Seria uma ética dos fracos, que favoreceria os que são incapazes de praticar a "individualidade", no sentido da autonomia competitiva liberal. Então, salienta o autor, a ideia de comunidade estaria, de certa forma, ligada à certeza, à segurança e à proteção. Mas o preço de tudo isso seria a perda da liberdade, e quando esta é sacrificada em nome da segurança, ela "tende a ser liberdade dos outros". De qualquer modo, com a comunidade, a democracia ganha um novo ponto de ancoragem.

A comunidade torna-se base para se pensar a participação como forma de vida, como um bem em si mesmo para as pessoas formadas em uma mesma tradição democrática. A identidade cidadá é pensada em seu nexo com a coletividade. O movimento comunitarista surge como crítica ao modelo liberal de sociedade, que supóe a autonomia da pessoa concebida abstratamente como livre e igual. O comunitarismo apresenta um 'eu' antípoda ao 'eu' liberal-iluminista. Ao 'eu' agência ou faculdade de conhecer, deliberar e agir "desengagée", livre e racional, enfim, independente de qualquer contexto, os comunitaristas opõem um 'eu' situado dentro de um contexto de compreensão de uma tradição. Os comunitaristas supõem que as sociedades são comunidades constituídas em vista de bens comuns. Para julgar se uma sociedade é justa não se deve apelar para um modelo abstrato de direitos universais, mas para a sua cultura, tradições, enfim o "mundo da vida" dessa sociedade. A concepção comunitarista é também "historicista" e refere-se sempre a um conteúdo. A uma ética de princípios e a uma democracia meramente procedimental, ela opõe uma ética das virtudes, e seu conceito fundamental é a ideia de bem comum a ser garantido pela participação. A justiça comunitária é definida conforme o mérito, desde que dado sempre no interior de um contexto social, onde é compreendido como alguma forma de excelência. A razão prática é contextualizada também no sentido de que ela não procura apenas construir fórmulas que dependem do contexto, mas também melhor articular o que o está implicado no contexto.

Para Taylor (2000), o "liberalismo não é um terreno de possível encontro para todas as culturas; ele é a expressão política de uma gama de culturas, sendo, sobretudo, incompatível com outras gamas" (p. 266). Assim, deve haver algum meio-termo entre a exigência não autêntica e homogeneizante do reconhecimento de igual valor, de um lado, e o autofechamento em padrões etnocêntricos de outro. Frente às outras culturas, é necessário o aprender a conviver, tanto em escala mundial, quanto no interior de cada sociedade.

Taylor propõe a política do reconhecimento como forma de se assumir as diferenças ao invés de neutralizá-las ou de jogá-las para o domínio do privado, como mera questão de preferência ou de bem que deve ser escolhido e implementado em conformidade com a moldura do justo, do direito. Nesse caso, o autor pressupõe um vínculo entre o reconhecimento e a identidade com as características fundamentais definidoras do que uma 
pessoa é. Essa identidade é moldada, sobretudo, conforme reconhecimentos ou não que um indivíduo recebe dos outros. "O não-reconhecimento ou o reconhecimento errôneo podem causar danos, podem ser uma forma de opressão, aprisionando alguém numa modalidade de ser falsa, distorcida e redutora" (2000, p. 241).

Os comunitaristas invertem as prioridades na concepção de pessoa frente à política. $\mathrm{Na}$ política da dignidade igual proposta pelos liberais, o que é estabelecido pretende ser universalmente o mesmo, "uma cesta idêntica de direitos e imunidades"; mas na política da diferença exige-se o reconhecimento da identidade peculiar de determinado grupo ou indivíduo, está em questão o que o distingue e não o que o iguala, ou o que coaduna com a identidade dominante ou majoritária (TAYLOR, 2000, p. 250-251). O comunitarismo, na visão de Taylor, supõe apenas um potencial universal, "o de formar e definir a própria identidade, tanto como indivíduo quanto como cultura” (p. 253). A dignidade não está na autonomia, na capacidade, tal como definida por Kant, de o agente racional dirigir a própria vida através de princípios. $O$ Estado, na acepção tayloriana, não se define meramente pela incumbência de promover o direito, um sistema que regule a convivência entre agentes livres, racionais e iguais na perspectiva da justiça. Ele é, sobretudo, o palco em que a luta pelo reconhecimento se expressa, tal como ocorre na prática das ações afirmativas. A diferença substantiva (particular e comunitária) deve vencer a igualdade universal do direito formal dos estados liberais. Perante isso, podem ser investigadas as pretensões ético-políticas da Secad (Secretaria de Educação Continuada, Alfabetização e Diversidade), criada em julho de 2004, cujo objetivo é o de promover a inclusão, o respeito e reconhecimento das diferenças no âmbito da política e gestão da educação.

Taylor (2000, p. 294) aponta para a necessidade da "autocompreensão" comunitária no processo democrático. Eis como ele concebe as exigências da democracia:

a) as pessoas envolvidas compreendem a si mesmas como pertencentes a uma comunidade que partilha alguns propósitos comuns e reconhece que seus membros partilham esses propósitos;

b) os vários grupos, tipos e classes de cidadãos são genuinamente ouvidos e podem impactar o debate;

c) a decisão que surge daí é na realidade a preferência da maioria.

A dimensão comunitária da democracia liga-se à convicção de que "ser ouvido" não é algo ligado ao mero intercâmbio particular de opiniōes, mas ao "estatuto do relacionamento com o todo" (TAYLOR, 2000, p. 294). Ser ouvido refere-se ao saber que se é valorizado de "certa maneira, mesmo quando certas exigências particulares não são atendidas" (TAYLOR, 2000, p. 294). Isso se define na relação entre a meta das pessoas "com os propósitos comuns e com as metas dos outros grupos com os quais elas sentem alguma solidariedade à luz desses propósitos” (TAYLOR, 2000, p. 294). Assim, o fato de 
as pessoas terem sido ouvidas não pressupõe que as exigências delas não sejam recusadas pelo coletivo, mas isso passa a ter sentido no âmbito da compreensão comum, dos valores compartilhados pela comunidade.

Para Taylor, essa forma de enfocar a democracia se distingue da tradição jacobinobolchevique, que toma a vontade do povo como algo unânime, "cuja divisão resulta de algum tipo de distorção: o regime de classe, ou o trabalho de facções" (2000, p. 293). O autor destaca o jacobinismo como uma tradição política incapaz de acomodar a diversidade, pois os seus defensores não podem compreender até que ponto uma sociedade política funciona como uma comunidade.

O comunitarismo valoriza a tradição e a cultura como fonte de diversidade humana. Pode-se dizer que o que serve para o Estado serve também para a escola. Já no início dos últimos anos oitenta, Sander (1984) captou com profundidade essa nova tendência. Segundo ele, isso remete à:

relação entre política e educação, segundo a qual a educação é uma das práticas sociais particulares da política como prática global da convivência humana. Na educação, a polis é a escola, a universidade e o sistema de ensino inseridos em seu meio cultural. É nessa polis que os seus participantes convivem para a prática da educação, que, nesse sentido, se torna uma prática essencialmente politica. É também nesse sentido que, consequentemente, a administração da polis educacional se torna um ato político, preocupando-se com os objetivos, a organização e as decisōes que afetam a convivência humana que se constrói na escola e na universidade através de permanentes convergências e divergências e de múltiplas sintonias e conflitos (p. 147-148. Grifos do autor).

Para a concepção comunitarista, a participação nas decisões coletivas é um bem a ser promovido, pois faz parte da natureza humana participar da vida política, sem o que o indivíduo não se realiza plenamente, torna-se alienado ou perde sua característica de ser livre, na medida em que a liberdade é entendida em seu sentido positivo de participação. Assim, a participação não é vista como um meio para garantir a autonomia liberal entendida como liberdade negativa de não interferência e liberdade de escolhas no mercado -, mas como um fim em si mesmo, como o exercício da autonomia, que, enquanto tal, é sempre política, sendo constitutiva da identidade das pessoas educadas numa forma de vida democrática.

A concepção comunitarista da educação pressupõe que deve haver um contínuo entre a cultura local e o currículo escolar. Os professores não poderiam ser agentes estranhos à comunidade, ensinando saberes e valores em virtude apenas de sua suposta universalidade, racionalidade e cientificidade. A identidade é formada a partir da pertença a uma comunidade, sem a qual uma pessoa não poderia descrever a si mesma. A escola, vista como entidade comunitária, é uma criação da comunidade local para responder às necessidades educativas específicas. As escolhas aparentemente individuais refletem o 
reconhecimento de deveres definidos coletivamente através de exemplos e companheirismos. Isso gera responsabilidades que mantêm a estabilidade social. A comunidade torna-se uma fonte de valores e o referencial para se definir a democracia e a formação humana. A legitimidade democrática não resulta de escolhas individuais ou da construção negociada de valores, mas é "essencialmente" um produto coletivo.

\section{LIMITES DAS DEMOCRACIAS CONTRATUALISTA E COMUNITARISTA}

Para o fundamentalismo, a escola é instrumento de propagação de uma única doutrina considerada verdadeira e absoluta. A escola seria o lugar da doutrinação, da discriminação e opressão de minorias. Nesse sentido a escola pode tornar-se o centro de ação de cruzadas moralizadoras e retrógradas, que em nome da tradição impõe verdades, molda condutas, inculcando diretamente valores. No prisma fundamentalista, a escola perderia o seu caráter multicultural e a democracia perderia seu caráter emancipatório, degradando-se numa forma de opressão da minoria pela maioria.

O separatismo é a solução mais violenta e excludente, pois se baseia na impossibilidade de um entendimento. A solução comunitarista contra a escola monocultural é o interculturalismo. Supôe-se a possibilidade de preservação da identidade comunitária local através do diálogo e de trocas com os outros. Essa atitude, muitas vezes relativista e pragmática, admite criar pontes e tornar as fronteiras mais permeáveis, sem a intenção de buscar pontos de vista comuns ou conversões mútuas, afirmando, assim, a diversidade.

Contudo, a radicalização e fragmentação da visão comunitarista tem levado a um ceticismo em relação às possibilidades de negociação na escola. Como produzir acordos e consensos quando as comunidades, grupos e tribos são concebidas como singularidades cujos valores e perspectivas são irredutíveis. Nesse caso, a diversidade se transforma em pluralidade. Segundo Silva (2000), trata-se de "aproximar a diferença do múltiplo e não do diverso":

Tal como ocorre na aritmética, o múltiplo é sempre um processo, uma operação, uma ação. A diversidade é estática, é um estado, é estéril. A multiplicidade é uma máquina de produzir diferenças (...) a diversidade limita-se ao existente. A multiplicidade estende e multiplica, prolifera, dissemina. A diversidade é um dado - da natureza ou da cultura. A multiplicidade é um movimento. A diversidade reafirma o idêntico. A multiplicidade estimula a diferença que se recusa a se fundir com o idêntico (p. 101).

A concepção de diversidade está na base de outra possibilidade da democracia, que tem propiciado o florescimento de concepçôes "anarquistas" da democracia, ou daquilo que Ortega (2000) destaca como "política da amizade”. Para essa concepção, as políticas públicas educacionais centralizadas e universalizáveis seriam sempre drásticas, tornandose mera ocasião de resistências espraiadas. Nesse âmbito, a ideia de autogestão ganha relevância desde que concebida como "uma nova forma de os indivíduos assumirem 
responsabilidades sobre suas atividades, sem intermediários, tendo o poder de influenciar no conteúdo de sua organização em diferentes esferas da vida econômica e social" (MARTINS, 2002, p. 35). Os trabalhadores assumiriam diretamente o poder, sem representação, indo da mera participação para a posse efetiva do poder local. $\mathrm{Na}$ atualidade, a fragmentação decorrente do relativismo dos valores comunitários alimenta e legitima as pretensóes da democracia anarquista, que passa a exaltar o indivíduo com seus desejos errantes como a única referência legitimadora de uma coletividade que caminha à deriva, onde democracia significa um experimento entre indivíduos, sempre aberto e sem regras estáveis.

$\mathrm{Na}$ democracia baseada na ideia de contrato social, supõe-se que o consenso resulta de negociações em uma condição ideal definida por procedimentos imparciais, ou pelo menos aceitos como tais pelos que deles participam. O contrato, regulador das decisões majoritárias seria uma forma de garantir que a maioria não oprimiria a minoria, uma vez que os contratantes pressupóem princípios razoáveis reguladores dos acordos. Mas o formalismo do contrato torna-o inviável na prática, uma vez que os indivíduos decidem sempre a partir de valores e tradições, e não meramente como cidadãos livres e iguais, o que impossibilita a aceitação de consensos universalizáveis. Segundo a concepção comunitarista, o consenso é algo dado pela tradição, cabendo ao processo democrático expressar a vontade cristalizada na comunidade que deve indicar o bem comum.

Mas a radicalização da democracia exige que se retome a base histórica e material dos modelos deliberativos, enfatizando a dimensão econômico-social da identidade, transpondo seu "horizonte" meramente "moral". Essa possibilidade tem sido, ideologicamente, cada vez mais associada ao jacobinismo e bolchevismo, como forma de desqualificar a democracia popular, associando-a também ao populismo. Contudo, cabe lembrar que o pluralismo democrático não é um apanágio do capitalismo, como mostra Coutinho (1984), e muito menos pode se efetivar de forma radical num sistema econômico baseado na opressão.

A emancipação humana passa em primeiro lugar pelo combate à exploração entre seres humanos. Assim, a luta pelo reconhecimento da diferença torna-se estéril, do ponto de vista da emancipação, quando não afronta os mecanismos de exploração inerentes à lógica do capitalismo. Isso exige uma crítica constante para que as possibilidades de emancipação humana não percam o seu eixo, que é o combate a uma economia perversa, cuja base é a cooptação de trabalhadores altamente qualificados, a exploração e o desemprego. Isso tem propiciado o restabelecimento de críticas marxistas que combatem a forma como os pós-modernos têm feito uma revolução conservadora ao centrar a discussão na questão das diferenças. Tal é o caso de Eagleton (1998), para quem as diferenças podem restringir a discussão em torno da emancipação, na medida em que não levam em conta que ninguém "tem um tipo de pigmentação da pele porque outra pessoa tem outra, nem é homem porque alguém mais é mulher, mas certas pessoas só são trabalhadores sem 
terra porque outros são senhores fazendeiros” (p. 63). Uma escola radicalmente comunitária não pode estar desvinculada de um projeto de superação das desigualdades sociais, caso contrário ela ficará sempre a meio caminho quando se limita à mera garantia de igualdades de oportunidades (modelo liberal) e ao reconhecimento do direito à diferença (modelo comunitarista).

O desafio das concepções radicais da democracia é o de superar a formação para uma autonomia e responsabilidade que significam meramente aceitar e adequar-se à realidade, reduzida ao jogo de forças do mercado, cuja lógica se impóe também ao político. O estranho é que tal imperativo neoliberal se impóe não como resultado de uma deliberação democrática - mesmo na forma de contrato falsificado - dos povos que adeririam alegremente ao consenso neoliberal, mas como produto de uma necessidade objetiva. Segundo Rancière (1996, p. 14-15):

O liberalismo supostamente reinante retoma do marxismo, tido como caduco, o tema da necessidade objetiva, identificada às coerçôes e aos caprichos do mercado mundial. Que os governos sejam simples agentes de negócios do capital internacional, essa tese outrora escandalosa de Marx, é hoje a evidencia quanto à qual "liberais" e "socialistas" concordam. A identificação absoluta da política com a administração do capital não é mais o segredo vergonhoso que as "formas" da democracia viriam mascarar, é a verdade declarada com a qual nossos governos se legitimam. Nessa legitimação, a demonstração de capacidade deve apoiar-se numa demonstração de impotência.

A concepção liberal da realidade passou a ser inquestionável e tomada como imutável. Estamos numa época em que a gestão "democrática" da educação tende a ser administração do capital humano e social, no sentido de formar cidadãos competitivos e virtuosos, civicamente empenhados na promoção da funcionalidade da democracia liberal, como reza o credo do fim da história.

\section{CONSIDERAÇÕES FINAIS}

Embora os referidos ideários de democracia - contratualista e comunitarista - sejam, aparentemente, incompatíveis entre si, eles não são incompatíveis com o capitalismo e com a sociedade regulada pelo mercado, o que torna a disputa entre eles uma (mera) disputa em família. Contudo, há propostas e experiências radicais de democracia, dirigidas para o resgate socialista da participação e da ideia de soberania popular, voltadas para imposição efetiva de restrições coletivas à globalização financeira e para o controle político da economia, sem o que os ajustes em busca da equidade, da igualdade de oportunidades e do reconhecimento não passarão de meros efeitos de superfície, pouco contribuindo para a democratização radical da sociedade e da educação.

O maior desafio ético-político para a gestão da educação continua sendo o de manter e criar formas de resistência a partir da situação concreta de trabalho e de vida, para 
romper e transpor as formas de despotismo, produto das relações sociais presentes no modelo econômico hegemônico e seus movimentos de reprodução. Trata-se de inquirir sobre as consequências das políticas educacionais no Brasil, sobretudo se elas projetam ou não uma identidade coletiva (ou a fragmenta) no sentido de efetivar a formação de uma cultura democrática, e até que ponto isso tem sido ou não o caso.

\section{Referências}

ACKERMAN, Bruce. Social Justice in the Liberal State. Bringhampton, NY: Yale University Press, 1980.

BAUMAN, Zygmunt. Comunidade. A busca da segurança no mundo atual. Trad.: Plínio Dentzien. Rio de Janeiro: Zahar, 2003.

BROUSEAU, Guy. Le contrat didactique: le milieu. Recherches en Didactique des Mathématiques, Grenoble (France), v. 9, n. 3, p. 309-336, 1988.

COUTINHO, Carlos Nelson. A democracia como valor universal e outros ensaios. 2. ed. Rio de Janeiro: Salamandra, 1984.

DAGNINO, Evelina; OLVERA, Alberto J.; PANFICHI, Aldo. Para uma outra leitura da disputa pela construção democrática na América Latina. In: ——; — - _ - (Orgs.). A disputa pela construção da democracia na América Latina. São Paulo: Paz e Terra; Campinas: Edunicamp, 2006. p. 261-307.

EAGLETON, Terry. As ilusōes do pós-modernismo. Trad.: Elizabeth Barbosa. Rio de Janeiro: Zahar, 1998.

FORQUIN, Jean-Claude. O currículo entre o relativismo e o universalismo. Educação e Sociedade, Campinas, v. 21, n. 73, p. 47-70, dez. 2000.

FOUREZ, A construção da ciência. São Paulo: Unesp, 1995.

GUTMAnN, Amy. A desarmonia da democracia. Lua Nova. Revista de Cultura e Política, São Paulo, n. 36, p. 5-37, 1995.

- Democratic education. Princeton: Princeton University Press, 1987.

MARTINS, Ângela. Autonomia da escola: a (ex)tensão do tema nas políticas públicas. São Paulo: Cortez, 2002.

MARX, Karl. A miséria da filosofia. Trad.: José P. Netto. São Paulo: Global, 1985.

OÑA, Fernando Vallespín. Nuevas teorias del Contrato Social: John Rawls, Robert Nozick y James Buchnan. Madrid: Alianza Editorial, 1985.

ORTEGA, Francisco. Para uma politica da amizade: Arendt, Derrida, Foucault. Rio de Janeiro: Relume Dumará, 2000.

PINTO, Neuza Bertoni. Contrato didático ou contrato pedagógico? Diálogo Educacional, Curitiba, v. 4, n. 10, p. 93-106, set./dez. 2003.

RANCIÈRE, Jacques. O desentendimento. Política e filosofia. Trad.: Ângela Leite Lopes. São Paulo: Ed. 34, 1996. 
ROMANO, Roberto. O caldeirão de Medeia. São Paulo: Perspectiva, 2001.

RUIZ SCHNEIDER, Carlos. Notas sobre comunitarismo, republicanismo y neoliberalismo. Revista de Derecho, Valdivia (Chile), v. 11, n. 1, p. 95-101, dic. 2000.

SANDER, Benno. Consenso e conflito. Perspectivas analíticas na pedagogia e na administração da educação. São Paulo: Pioneira, 1984.

SANTOS, Boaventura de Sousa. Reinventar a democracia: entre o pré-contratualismo e o póscontratualismo. In: OLIVEIRA, Francisco; PAOLI, Célia (Orgs.). Os sentidos da democracia. Políticas do dissenso e hegemonia global. Petrópolis: Vozes, 1999, p. 83-p. 129.

SILVA, Tomaz Tadeu da. A produção social da identidade e da diferença. In: (Org.).

Identidade e diferença. A perspectiva dos estudos culturais. Petrópolis: Vozes, 2000. p. 73-102.

TAYLOR, Charles. Argumentos filosóficos. Trad.: Adail Sobral. São Paulo: Loyola, 2000.

TEDESCO, Juan Carlos. O novo pacto educativo: educação, competitividade e cidadania na sociedade moderna. Trad.: Otacílio Nunes. São Paulo: Ática, 1998.

TORRES, Carlos Alberto. Democracia, educação e multiculturalismo. Petrópolis: Vozes, 2001. 


\section{Education in face of liberal and communitarian tendencies of democracy} Abstract

The aim of this paper is to set in contrast some models of democracy in order to investigate the educational management, discussing the heuristic potential of those models for the comprehension of the challenges of democratic school administration and the way educational policies are conceived and implemented in the public school. The contractualist or liberal democracy and its communitarianist or participatory conception are dealt with. These conceptions, despite the fact that they set over against each other, intersect and need one another in order to selfdefine themselves, as a part of the same ethical-political family. In spite of its criticism to individualism and to the logic of the social contract as a base for democracy, the communitarian conception is not compatible with the exigencies of capitalism, thus allowing it to rearticulate politically using new ethical foundations.

Keywords: Ethical and political models. Democracy. Educational management.

\section{L'éducation face aux tendences libérales et communautaires de la démocratie} Résumé

L'objectif de ce texte est de faire le contrepoids entre les modèles de démocratie pour investiguer la gestion de l'éducation, discutant le potentiel heuristique de ceux-ci pour la compréhension des défis de l'administration démocratique de l'enseignement et de la forme comme les politiques éducationnelles sont conçues et implémentées dans l'école publique. La conception contratualiste ou libérale de la démocratie et la conception communautariste ou participative sont abordées. L'on montre que ces conceptions, pour autant qu'elles font le contrepoids entre elles, s'entrecroisent et ont besoin l'une des autres pour s'autodéfinir, faisant partie d'une même famille éthique-politique. En dépit de sa critique à l'individualisme et à la logique du contrat social comme base pour la démocratie, la conception communautariste n'est pas compatible avec les exigences du capitalisme, permettant à celui-ci de se réarticuler politiquement à partir de nouvelles bases éthiques.

Mots clefs : Modèles éthiques-politiques. Démocratie. Gestion de l'éducation.

\section{La educación frente a las tendencias liberal y comunitarista de la democracia} Resumen

El objetivo de este texto es contraponer modelos de democracia para investigar la gestión de la educación, discutiendo el papel heurístico de los mismos en la comprensión de los desafios de la administración democrática de la enseñanza y de la forma como las políticas educacionales son concebidas e implementadas en la escuela pública. Son abordadas la concepción contratualista o liberal de la democracia y su concepción comunitarista o participativa. Se muestra que esas concepciones, por más que se contrapongan entre si, se entrecruzan y necesitan una de las otras para se autodefinir, haciendo parte de una misma familia eticopolitica, pese a su crítica al individualismo y a la lógica del contrato social como base para la democracia, la concepción comunitarista no es incompatible con las exigencias capitalistas, permitiendo la rearticulación politica a partir de nuevas bases éticas.

Palabras-clave: Modelos eticopolíticos. Democracia. Gestión de la educación.

Recebido em: 15.05.2008

Aceito em: 05.05.2009 
